\title{
PENENTUAN KONDISI KESEIMBANGAN UNIT LEACHING PADA PRODUKSI EUGENOL DARI DAUN CENGKEH
}

\author{
Tagora Bangkit P.S, Rinaldry Sirait, Iriany \\ Departemen Teknik Kimia, Fakultas Teknik, Universitas Sumatera Utara, \\ Jl. Almamater Kampus USU Medan 20155, Indonesia \\ Email : tagorabangkit@yahoo.com
}

\begin{abstract}
Abstrak
Daun cengkeh merupakan sumber alternatif untuk mendapatkan minyak cengkeh. Minyak cengkeh tergolong ke dalam minyak atsiri dengan komponen utamanya eugenol. Minyak cengkeh banyak digunakan dalam industri farmasi, makanan dan minuman. Penelitian ini bertujuan untuk mendapatkan minyak cengkeh dengan ekstraksi padat cair (leaching). Dengan dilakukannya penelitian ini diharapkan dapat memberikan data-data keseimbangan fase padat cair untuk perancangan alat ekstraktor. Penelitian dilakukan dengan proses ekstraksi menggunakan pelarut etanol kemudian dilanjutkan dengan proses destilasi untuk memisahkan minyak dari pelarut. Variabel tetap yang digunakan dalam penelitian ini adalah kecepatan pengadukan 460 rpm dan berat daun cengkeh basis kering 90 gram. Sedangkan variabel berubahnya adalah suhu ekstraksi $30^{\circ} \mathrm{C}$ dan $50^{\circ} \mathrm{C}$, waktu ekstraksi $1 \mathrm{jam}, 1,5 \mathrm{jam}, 2 \mathrm{jam}, 2,5 \mathrm{jam}$ dan $3 \mathrm{jam}$, dan jumlah pelarut $500 \mathrm{ml}$ dan $600 \mathrm{ml}$. Hasil penelitian menunjukkan bahwa rendemen hasil ekstraksi tertinggi dapat diperoleh pada suhu $50^{\circ} \mathrm{C}$ dan volume $600 \mathrm{ml}$, waktu keseimbangan tercapai setelah 2,5 jam, dan kadar eugenol $79 \%$.
\end{abstract}

Kata kunci : leaching, destilasi, minyak cengkeh, rendemen, eugenol

\begin{abstract}
Leafs of clove is an alternative source to obtain clove oil. Clove oil is classified into essential oil with eugenol as its main component. Clove oil is widely used in pharmaceutical, food and beverage industries. The objective of this research is to obtain clove oil by solid-liquid extraction (leaching). This research was expected to give data of solid-liquid equilibrium for designing solid liquid extractor. This research was carried out by leaching process with ethanol as its solvent. The extract was then purified by distillation to separate solvent from oil. The fixed variables which were used in this research were stirring rate of $460 \mathrm{rpm}$ and 90 grams dry-based clove leaf. Extraction process was carried out by using solvent with temperature of $30^{\circ} \mathrm{C}$ and $50^{\circ} \mathrm{C}$, extraction time of $1-3$ hours with 0.5 hour increment and solvent volume of $500 \mathrm{ml}$ and $600 \mathrm{ml}$. The results showed that the highest yield of clove oil extraction was obtained at temperature of $50^{\circ} \mathrm{C}$ and solvent volume of $600 \mathrm{ml}$. Equilibrium was reached after 2.5 hours and $79 \%$ eugenol concentration in the solvent.
\end{abstract}

Keywords : leaching, distillation, clove oil, yield, eugenol

\section{Pendahuluan}

Indonesia adalah salah satu pusat keanekaragaman hayati dunia disamping Brazilia dan Tanzania. Dari Sabang sampai Merauke tersebar sekitar 40.000 jenis tumbuhan. Namun dari sekian banyak jenis tumbuhan tersebut, masih sangat sedikit yang diteliti sebagai penghasil minyak atsiri [1]. Indonesia mempunyai potensi sebagai penghasil minyak atsiri yang berlimpah. Produksi minyak atsiri baru pada tahap menghasilkan minyak kasar (crude oil) [7]. Sekitar tahun 2000, produk minyak atsiri mulai dikembangkan untuk memperoleh turunannya yang dapat digunakan sebagai feromon, aditif biodiesel, antioksidan, polimer, aromaterapi, penjerap logam, sun screen block dan banyak lagi kegunaan. Kemampuan untuk melakukan konversi komponen minyak atsiri menjadi senyawa-senyawa yang lebih berguna merupakan suatu hal penting yang mendesak sekarang. Hal ini disebabkan senyawa turunan minyak atsiri yang diimpor oleh Indonesia harganya jauh lebih mahal daripada harga minyak atsiri yang diekspor oleh Indonesia.

Minyak cengkeh merupakan salah satu jenis minyak atsiri yang dapat diperoleh dari bagian tanaman cengkeh. Minyak cengkeh tersebut diambil dari bunga maupun daun cengkeh. Kadar minyak di dalam bunga cengkeh berkisar $17-18 \%$ sedangkan pada daun sekitar 2-3\% [5]. Pemanfaatan bunga cengkeh sebagai sumber minyak sudah banyak dimanfaatkan. Namun belakangan ini harga bunga cengkeh mencapai Rp83.000,- per kilogram [10] yang mengakibatkan petani cengkeh lebih memilih menjual bunganya daripada mengolahnya. Oleh karena itu pada penelitian ini mencari sumber 
minyak cengkeh yang lain yang masih potensial yaitu daun cengkeh. Berdasarkan tinjauan langsung di lapangan, daun cengkeh yang telah jatuh, biasanya hanya dikumpulkan dan dibakar. Oleh karena itu, pengambilan minyak dari daun cengkeh cukup potensial untuk dilakukan.

Salah satu cara pengambilan minyak dalam daun cengkeh adalah ekstraksi dengan pelarut yang mudah menguap, seperti kloroform, eter, aseton, heksana atau alkohol [4]. Ekstraksi minyak daun cengkeh dengan menggunakan alkohol menghasilkan rendemen yang lebih tinggi [3]. Pada proses leaching, terjadi difusi minyak dari dalam daun cengkeh ke fasa cair yaitu pelarut dan minyak akan terjadi keseimbangan dimana pada keadaan ini minyak dalam daun cengkeh tidak dapat mendifusi lagi ke pelarut. Parameter penting dalam ekstraksi padat cair adalah koefisien transfer massa dan tetapan keseimbangan. Tetapan keseimbangan menunjukkan nisbah minimum antara pelarut dengan padatan yang diekstraksi [8].

Data-data keseimbangan fase padat cair pada proses leaching minyak daun cengkeh belum banyak tersedia. Sementara itu, untuk perancangan alat ekstraktor membutuhkan data keseimbangan. Data keseimbangan menunjukkan rasio minimum antara pelarut yang dibutuhkan dan daun cengkeh yang diekstraksi.

\section{Teori}

Pengertian atau definisi minyak atsiri yang ditulis dalam Encyclopedia of Chemical Technology menyebutkan bahwa minyak atsiri merupakan senyawa, yang pada umumnya berwujud cairan, yang diperoleh dari bagian tanaman, akar, kulit, batang, daun, buah dan biji maupun dari bunga dengan cara penyulingan dengan uap [11]. Tidak semua jenis tumbuhan menghasilkan minyak atsiri, hanya tumbuhan yang memiliki sel glanula sajalah yang bisa menghasilkan minyak atsiri. Minyak cengkeh merupakan minyak atsiri yang diperoleh dari tanaman cengkeh (Syzigium caryophyllatum (L.)). Kualitas minyak cengkeh dievaluasi dari kandungan fenol, terutama eugenol. Kandungan eugenol dalam minyak bunga, gagang dan daun cengkeh sangat dipengaruhi oleh keadaan bahan baku, metode penyulingan minyak dan pengambilan eugenol dari minyak [6]. Konstituen minyak daun cengkeh dapat dibagi menjadi dua kelompok. Kelompok pertama merupakan senyawa fenolat dan eugenol yang merupakan komponen yang paling besar. Senyawa ini mudah diisolasi dengan $\mathrm{NaOH}, \mathrm{KOH}, \mathrm{Ca}(\mathrm{OH})_{2}$ dan kemudian dinetralkan dengan asam mineral. Kelompok kedua mengandung senyawa-senyawa non fenolat yaitu $\beta$-kariofilen, $\alpha$-kubeben, $\alpha$-kopaen, hulumen, $\delta$-kadien, dan kadina 1,3,5-trien [12].
Suatu sistem disebut dalam keadaan setimbang (equilibrium state) bila harga semua variabel termodinamikanya tidak berubah dengan waktu, dan di dalam sistem tidak ada gradien harga variabel-variabel intensifnya [9].

Pada proses pengambilan minyak dari fase padat melalui tiga tahap [13], yaitu :

1. Difusi solute dari padatan ke permukaan padatan,

2. Kesetimbangan fase,

3. Perpindahan massa dari permukaan padatan ke pelarut.

Skema difusi padat cair diberikan pada gambar 1 di bawah ini [4]

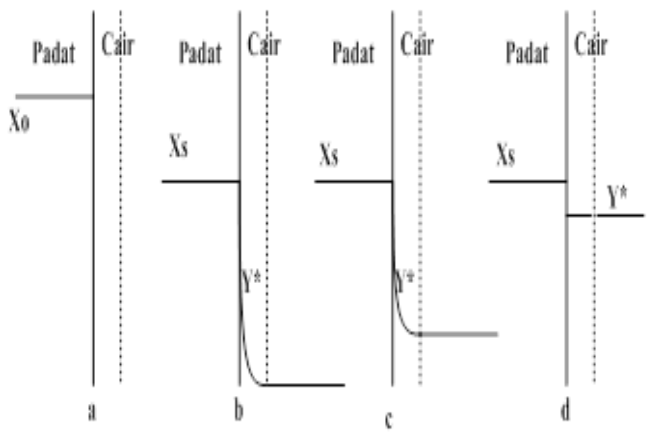

Gambar 1. Skema difusi padat cair

Peristiwa dalam gambar 1 dijelaskan sebagai berikut.

a. Mula-mula pada saat $\mathrm{t}=0$, konsentrasi minyak dalam padatan Xo dan di fase cair (pelarut) belum mengandung minyak.

b. Peristiwa leaching setiap saat.

c. Peristiwa leaching setiap saat lebih lama dibandingkan gambar $b$.

d. Kesetimbangan dianggap tercapai bila konsentrasi minyak dalam cairan tetap sama dengan $\mathrm{Y}^{*}$.

\section{Metodologi Penelitian}

Bahan baku yang digunakan dalam penelitian ini adalah daun cengkeh kering dan bahan kimia berupa etanol $\left(\mathrm{C}_{2} \mathrm{H}_{5} \mathrm{OH}\right)$, natrium hidroksida $(\mathrm{NaOH})$ dan air $\left(\mathrm{H}_{2} \mathrm{O}\right)$. Daun cengkeh dikeringkan di ruangan terbuka dan diukur kadar airnya. Percobaan pendahuluan ini untuk penentuan waktu kesetimbangan. Penentuan waktu setimbang dilakukan dengan cara mengekstraksi 90 gram daun cengkeh dalam etanol $96 \%$ dengan volume $500 \mathrm{ml}$. Leaching berlangsung pada suhu $30^{\circ} \mathrm{C}$ dan putaran pengaduk $460 \mathrm{rpm}$. Leaching dilakukan dengan waktu 1 dan 3 jam. Pada akhir leaching, ampas daun dipisahkan dari campuran dengan cara menyaring. Pada waktu setimbang, ketika rendemen minyak relatif tidak berubah terhadap waktu. 
Percobaan utama untuk mengetahui pengaruh suhu, volume etanol dan waktu proses leaching terhadap rendemen. Percobaan dilakukan dengan variasi suhu $30^{\circ} \mathrm{C}$ dan $50^{\circ} \mathrm{C}$ dan variasi jumlah volume etanol pada konsentrasi $96 \%$ yaitu 500 dan 600 ml. Rangkaian alat yang digunakan seperti gambar 2 .

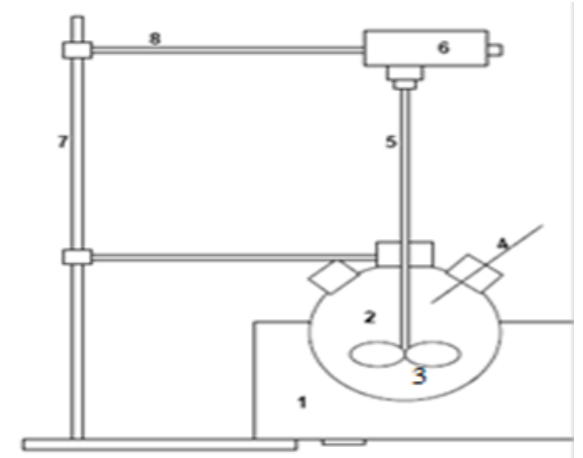

Gambar 2. Rangkaian peralatan leaching

Keterangan :

1. Heating mantle

2. Labu leher tiga

3. Impeller

4. Termometer

5. Batang poros

6. Mixer

7. Statif

8. Klem

Kemudian dilakukan tahap penyulingan untuk memisahkan minyak dengan pelarut dilangsungkan pada temperatur $78^{\circ} \mathrm{C}$. Kadar minyak dalam daun dihitung dengan neraca massa total dalam beaker

$\mathrm{Cs}=\frac{C o . M-C a . V}{M}$ (1)

Dimana :

$\mathrm{Cs}=$ kadar minyak dalam daun selama leaching, gr minyak/gr daun.

$\mathrm{Co}=$ kadar minyak di dalam daun sebelum leaching yang ditentukan dengan metode ekstraksi soxhlet, gr minyak/gr daun.

$\mathrm{Ca}^{*}=$ kadar minyak dalam etanol pada keadaan kesetimbangan, gr minyak/ml etanol.

$\mathrm{M}=$ berat daun basis kering, $\mathrm{gr}$.

$\mathrm{V}=$ volume etanol, $\mathrm{ml}$.

Kemudian dilakukan tahap ekstraksi untuk menentukan kadar eugenol dalam minyak dengan menggunakan larutan basa $\mathrm{NaOH} 5 \%$.

\section{Hasil}

Data hasil percobaan utama yaitu massa minyak yang diperoleh setelah proses destilasi dapat dilihat pada tabel 1.
Tabel 1. Data hasil rendemen

\begin{tabular}{|c|c|c|c|}
\hline $\mathrm{V}_{\mathrm{l}}(\mathrm{ml})$ & $\mathrm{t}$ (menit) & $\mathrm{T}\left({ }^{\circ} \mathrm{C}\right)$ & $\begin{array}{c}\text { Rendemen } \\
(\%)\end{array}$ \\
\hline \multirow{8}{*}{500} & 60 & \multirow{5}{*}{30} & 1,26 \\
\hline & 90 & & 1,99 \\
\hline & 120 & & 2,01 \\
\hline & 150 & & 2,87 \\
\hline & 180 & & 1,47 \\
\hline & 120 & \multirow{3}{*}{50} & 3,73 \\
\hline & 150 & & 4,30 \\
\hline & 180 & & 3,87 \\
\hline \multirow{8}{*}{600} & 60 & \multirow{5}{*}{30} & 2,28 \\
\hline & 90 & & 3,10 \\
\hline & 120 & & 3,43 \\
\hline & 150 & & 3,47 \\
\hline & 180 & & 1,03 \\
\hline & 120 & \multirow{3}{*}{50} & 4,41 \\
\hline & 150 & & 4,60 \\
\hline & 180 & & 3,31 \\
\hline
\end{tabular}

\section{A. Pengaruh volume etanol}

Tabel 1 menunjukkan bahwa jumlah etanol berpengaruh terhadap rendemen minyak hasil ekstraksi. Pelarut etanol dengan rumus $\mathrm{C}_{2} \mathrm{H}_{6} \mathrm{O}$ memiliki ikatan kovalen polar. Atom $\mathrm{O}$ yang memiliki 2 pasang elektron menyendiri, 1 elektron berikatan dengan $\mathrm{CH}_{2}$ dan 1 elektron lagi berikatan dengan atom $\mathrm{H}$ memiliki rapat elektron yang sangat tidak merata. Etanol yang polar dapat mengekstrak minyak yang non polar karena etanol mengekstrak gugus ester $\left(\mathrm{COO}^{-}\right)$yang terdapat dalam minyak [13].

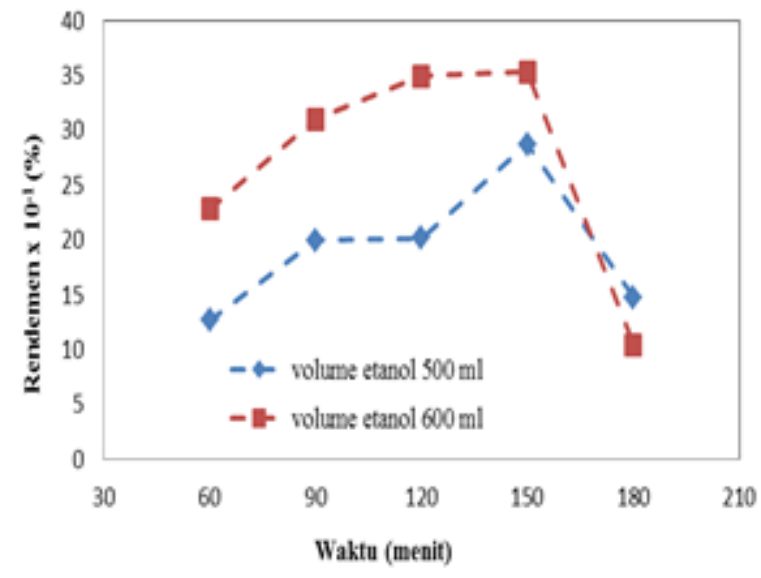

Gambar 3. Pengaruh waktu terhadap rendemen dengan variasi volume etanol

Dari gambar 3 dapat dilihat bahwa semakin banyak pelarut yang digunakan maka rendemen yang 
diperoleh semakin besar. Hal ini disebabkan semakin besarnya rasio pelarut terhadap daun maka luas permukaan perpindahan massa antara padatan dengan larutan semakin besar [4].

\section{B. Pengaruh temperatur}

Tabel 1 menunjukkan bahwa temperatur berpengaruh terhadap rendemen minyak hasil leaching.

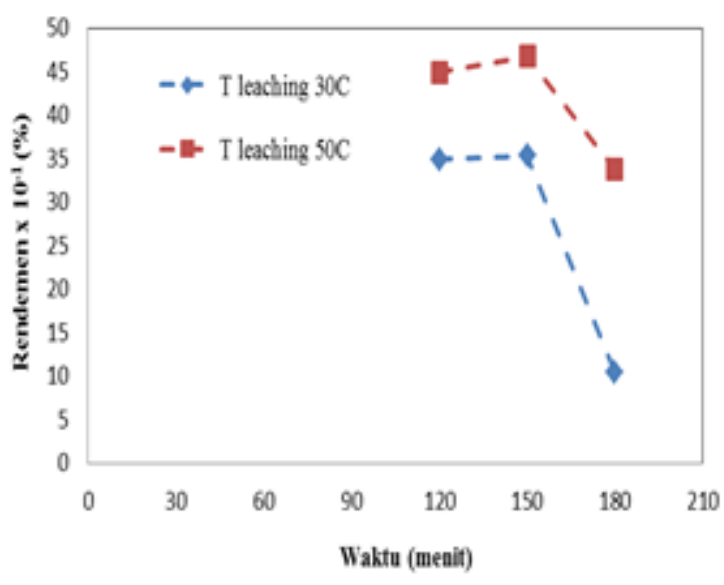

Gambar 4. Hubungan waktu dengan rendemen dengan variasi suhu operasi

Dari gambar 4, dapat dilihat bahwa semakin tinggi suhu ekstraksi maka rendemen yang dihasilkan akan semakin besar. Hal ini disebabkan rendemen cenderung meningkat karena kenaikan suhu mengakibatkan poripori pada daun cengkeh cenderung lebih terbuka sehingga difusi minyak berlangsung lebih cepat karena hambatan difusinya lebih kecil. Selain itu, ekstraksi padat cair, (leaching) dilakukan pada suhu yang tinggi karena semakin tinggi temperatur, semakin besar konsentrasi solute dalam pelarut. Hal ini disebabkan semakin tinggi temperatur maka viskositas akan semakin rendah dan difusitas solute akan semakin tinggi sehingga semakin cepat dan semakin banyak solute yang berpindah.

\section{Penentuan waktu kesetimbangan}

Kesetimbangan terkait dengan proses pengamatan dan waktu. Ketidakberubahan harga variabel-variabel termodinamika suatu sistem dengan waktu merupakan syarat yang perlu agar suatu sistem setimbang [9].

Dari gambar 5 dapat dilihat bahwa hubungan $\mathrm{t}$ (waktu) dengan data $\mathrm{C}_{\mathrm{A}}$. Kenaikan $\mathrm{C}_{\mathrm{A}}$ mula-mula besar karena minyak yang terkandung dalam padatan masih cukup besar atau dengan kata lain gradien konsentrasi solute diantara padatan dan di solven cukup besar, selanjutnya kenaikan $\mathrm{C}_{\mathrm{A}}$ semakin kecil sampai akhirnya
$\mathrm{C}_{\mathrm{A}}$ maksimum pada waktu 150 menit. Hal ini berarti waktu kesetimbangan untuk pelarut etanol adalah 150 menit.

Pada waktu 150 menit menunjukkan bahwa telah terjadi kesetimbangan antara konsentrasi minyak dalam padatan dan cairan di mana dapat disimbolkan sebagai $\mathrm{C}_{\mathrm{A}} *$.

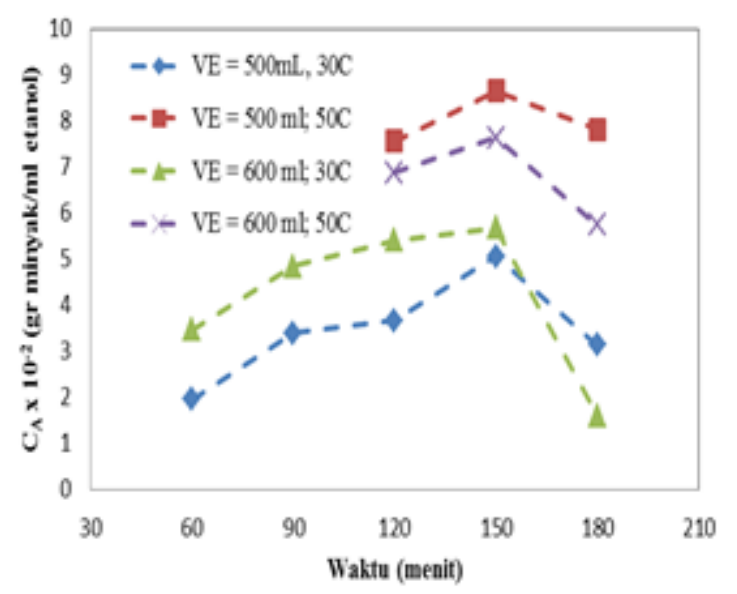

Gambar 5. Pengaruh konsentrasi minyak dalam fasa cairan terhadap waktu

Lamanya waktu proses ekstraksi sangat berpengaruh terhadap minyak yang dihasilkan. Pada keadaan setimbang, yang mempunyai nilai sama adalah potensial kimia dari kedua fase, bukan konsentrasi, sehingga transfer solute menjadi terhenti [14].

Kenaikan waktu proses yang digunakan menghasilkan kenaikan jumlah minyak yang dihasilkan. Lamanya waktu akan mempermudah penetrasi pelarut kedalam bahan baku, kelarutan komponen-komponen minyak cengkeh berjalan dengan perlahan sebanding dengan kenaikan waktu, akan tetapi setelah mencapai waktu optimal jumlah minyak yang terambil mengalami penurunan. Hal ini disebabkan komponen minyak pada bahan baku jumlahnya terbatas dan pelarut yang digunakan mempunyai batas kemampuan untuk melarutkan bahan yang ada, sehingga walaupun waktu ekstraksi diperpanjang solute yang ada pada bahan sudah tidak dapat melarut lagi. Di samping itu dengan penambahan waktu akan terjadi dekomposisi dari komponen-komponen selain minyak termasuk di dalamnya impuritas yang menyebabkan perubahan sifat komponen tersebut misalnya titik didih komponen baru lebih rendah dari titik didih komponen sebelumnya sehingga menjadi lebih mudah menguap dan akhirnya rendemen yang diperoleh berkurang [5]. 


\section{Penentuan kadar eugenol}

Eugenol reaktif terhadap basa kuat khususnya $\mathrm{NaOH}$. Sifat ini dimanfaatkan untuk mengambil eugenol dari minyak daun cengkeh. Minyak daun cengkeh sebanyak $10 \mathrm{ml}$ direaksikan dengan $\mathrm{NaOH}$ berlebih sehingga membentuk natrium eugenolat yang larut dalam air. Pada reaksi ini hanya eugenol yang bereaksi dengan $\mathrm{NaOH}$. Reaksi antara eugenol dengan $\mathrm{NaOH}$ merupakan reaksi yang cepat mencapai kesetimbangan [6]. Reaksinya adalah sebagai berikut :

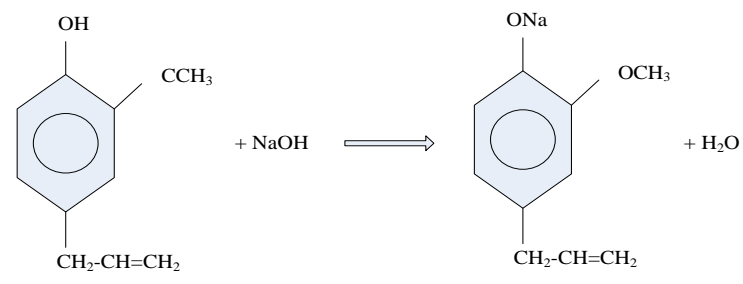

Gambar 6. Reaksi eugenol dengan $\mathrm{NaOH}$

Ada dua fenomena sekaligus yang terlibat dalam reaksi pengambilan eugenol dari minyak cengkeh, yaitu ekstraksi dan reaksi kimia. Eugenol berpindah dari fasa kariofilin ke fasa air sebagai proses ekstraksi dan selanjutnya eugenol dalam air akan bereaksi dengan $\mathrm{NaOH}$.

Penentuan kadar eugenol mengikuti rumus:

Kadar eugenol $=10 \% \times(10-$ jumlah minyak tidak larut).... ...[5]

Dengan jumlah minyak tak larut sebanyak $2,1 \mathrm{ml}$, maka diperoleh kadar eugenol sebesar 79\%.

\section{Kesimpulan}

1. Waktu kesetimbangan untuk ekstraksi padat cair tercapai saat 150 menit

2. Volume etanol $600 \mathrm{ml}$ menghasilkan rendemen lebih tinggi daripada volume etanol $500 \mathrm{ml}$

3. Suhu ekstraksi $50^{\circ} \mathrm{C}$ menghasilkan rendemen lebih baik daripada suhu ekstraksi $30^{\circ} \mathrm{C}$ pada waktu terbaik

4. Kadar eugenol diperoleh $79 \%$

\section{Daftar Pustaka}

[1] Agusta, Andria. Minyak Atsiri Tumbuhan Tropika Indonesia. Bandung : Penerbit ITB. 2000.

[2] Artati, Enny Kriswiyanti dan Fadilah. Pengaruh Kecepatan Putar Pengadukan dan Suhu Operasi pada Ekstraksi Tanin dari Jambu Mete dengan Pelarut Aseton. Jurnal Ekuilibrium. Volume 6. No 1. Hal 33-38. Surakarta. 2007.
[3] Darmawan, Petrus. Pengaruh Jenis Pelarut terhadap Rendemen Minyak Bunga Cengkeh dengan Menggunakan Metode Ekstraksi Soxhletasi. Jurnal Kimia dan Teknologi. Hal 283-287. 2000

[4] Distantina, Sperisa, Fadilah, Endah R., Dyartanti, dan Enny K. Artati. Pengaruh Rasio Berat Rumput Laut-Pelarut terhadap Ekstraksi Agar-Agar. Jurnal Ekuilibrium. Vol 6. No 2. Hal 53-58. Surakarta. 2007.

[5] Guenther, Ernest. Minyak Atsiri. Jilid I. Jakarta : Penerbit Universitas Indonesia. 1987.

[6] Hidayati, Nur. Ekstraksi Eugenol dari Minyak Daun Cengkeh. Jurnal Teknik Gelagar. Vol. 14. No 2. Hal 108-114. 2003.

[7] Nurhasanah, Siti, Efri Mardawati, Marleen Herudiyanto. Pemisahan Eugenol dari Minyak Cengkeh dengan Cara Distilasi Fraksinasi. Jurusan Teknologi Industri Pangan. Universitas Padjajaran. Bandung. 2005.

[8] Perry, Robert H., dan Don W. Green. Perry's Chemical Engineers' Handbook. Edisi ke8. McGraw Hill Book Company. New York : 2008.

[9] Rahayu, Susanto Imam. Termodinamika. Azas Dasar dan Terapan Kimia. Bandung : Penerbit ITB. 2006.

[10] Sasmita, Emit. Harga Cengkeh. 2012. http : http://regional.kompas.com/read/2012/07/ 28/1123398/Panen.Melimpah..Harga.Cen gkeh.Anjlok (Diakses 30 Agustus 2012)

[11] Sastrohamidjojo, Hardjono. Kimia Minyak Atsiri. Cetakan Pertama. Yogyakarta : Gajah Mada University Press. 2004.

[12] Sudarmi, Sri dan Siswanti. Koefisien Transfer Massa pada Ekstraksi Biji Pala dengan Pelarut Etanol. Prosiding Seminar Nasional Teknik Kimia "Kejuangan" Pengembangan Teknologi Kimia untuk Pengolahan Sumber Daya Alam Indonesia. Yogyakarta. 2011.

[13] Tedjawicaksana, Teddy. Pengaruh Temperatur dan Jenis Pelarut terhadap Pembuatan Minyak Kelapa Sawit dengan Ekstraksi Semikontinu. Laporan Hasil Penelitian. Departemen Teknik Kimia. Universitas Katolik Parahyangan. Bandung, 2004.

[14] Treyball, R.E. Mass Transfer Operations. Edisi Ketiga. McGraw Hill International Edition. Singapore : 1984. 